\title{
III. THE FATE OF CITRATE IN ERYTHROBLASTOTIC INFANTS TREATED WITH EXCHANGE TRANSFUSION ${ }^{1,2}$
}

\author{
By IRVING B. WEXLER, JOSEPH B. PINCUS, SAMUEL NATELSON, \\ AND JULIUS $\mathrm{K}$. LUGOVOY
}

\author{
(From the Department of Pediatrics and the Department of Biochemistry, \\ The Jewish Hospital of Brooklyn, Brooklyn, New York)
}

(Received for publication September 15, 1948)

Since the adoption of exchange transfusion as a method in the treatment of newborn infants with severe erythroblastosis (1-3) the question of the possible toxic effects of sodium citrate added to the administered blood, to prevent coagulation, has arisen (4). In this procedure from 85 to $95 \%$ of the infant's Rh-positive erythrocytes are replaced by the donor's Rh-negative erythrocytes depending upon the volume of blood that is administered and simultaneously removed (5). In order to effectuate an exchange of $85 \%$, a quantity of blood equivalent to twice the infant's blood volume must be used, and for an exchange of $98 \%$, a quantity of blood equivalent to four times the blood volume must be used. Since the average newborn infant has a blood volume in the range of 250-300 $\mathrm{ml}$. the procedure involves the use of approximately $500 \mathrm{ml}$. and approximately $1,000 \mathrm{ml}$., respectively. With the use of sodium citrate as an anticoagulant the infant receives as much as 60 to $120 \mathrm{ml}$. of a $3 \%$ solution of sodium citrate intravenously over a period of about $1 \frac{1}{2}$ hours.

In the experimental animal, the intravenous administration of large quantities of sodium citrate has been shown to produce convulsions (6). This has been ascribed to the formation of a poorly ionized calcium citrate complex which removes calcium ion from the blood stream (7-9). Despite this consideration, exchange transfusions have been successfully carried out in a large number of cases, although occasionally deaths have been reported in the very severely affected cases (10).

In order to study the adjustment that the newborn makes to the physiological strains to which it is subjected when an exchange transfusion is

1 The third in a series on the mechanism controlling citric acid levels in the blood. The first two papers in this series appeared in the Journal of Clinical Investigation, Vol. 27, pages 446 and 450, 1948.

2 This paper was presented at the Washington meeting of the American Chemical Society, August 30, 1948. carried out, citric acid, calcium, phosphorus, protein and total base levels were studied before, during and after such a transfusion on a newborn with no symptoms of erythroblastosis and with apparent normal hepatic and kidney function. The newborn studied was a mongolian idiot born in normal delivery. In addition citric acid determinations were carried out on serial bloods withdrawn from eight erythroblastotic infants during exchange transfusion.

$500 \mathrm{ml}$. of blood were freshly drawn from a compatible donor. To this were added $60 \mathrm{ml}$. of $3 \%$ sodium citrate (dihydrate of tri-sodium citrate). This made a total volume of $560 \mathrm{ml}$. Over a period of approximately 60 minutes $500 \mathrm{ml}$. of. this citrated blood were infused into the saphenous vein at the ankle. After $60 \mathrm{ml}$. had been infused the radial artery was cut and the blood was collected in $60 \mathrm{ml}$. portions, during the progress of the transfusion. The first $60 \mathrm{ml}$. were added without removal of blood in order to dilate the blood vessels and make the radial artery more apparent. The cells were separated by centrifuging and the plasma was analyzed for the various blood constituents.

Citrate determinations were carried out by a method previously described $(11,12)$. Calcium was done by direct precipitation from plasma (13) without ashing. Where citrate was at a high level the results were later shown to be significantly low because of the interference of citrate with calcium precipitation. The determinations could not be repeated with ashing subsequently because calcium salts were found precipitated in the plasma on standing. The calcium results were discarded and are not reported except where the citrate levels were low enough so as not to interfere, or where analysis was done by ashing on plasma from freshly drawn blood. Phosphorus was determined colorimetrically (14), total protein by a modified biuret method (15) and total base by electrodialysis (16).

The results obtained on the blood of the donor with added citrate, and on that of the newborn with no symptoms of erythroblastosis are shown before and after the tranfusion in Table I. The results are averages of duplicates. Standards and recovery of added amounts of the constituents 
TABLE I

Comparison of citrated adult blood plasma with that of the blood plasma of the infant before and after the exchange transfusion

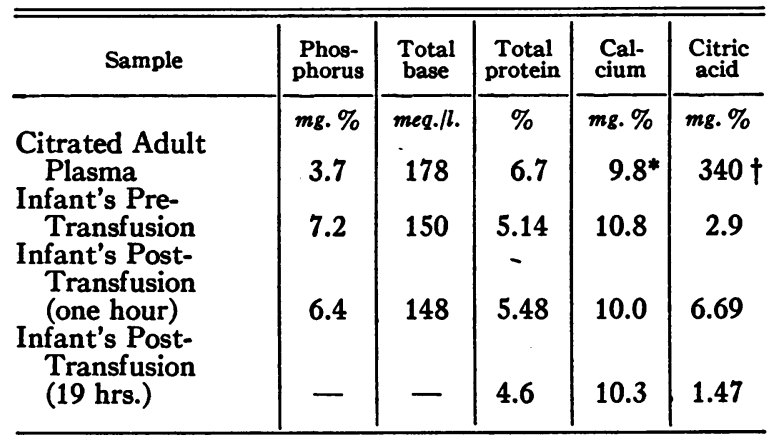

* Determination on ashed plasma.

$\dagger$ Assuming a $40 \%$ hematocrit and no citric acid in the red cells the total citric acid added in $500 \mathrm{ml}$. of whole citrated blood would be: $5 \times 340 \times 0.6=1,020 \mathrm{mg}$.

were also run. The results are in error by less than $5 \%$. Calculations in the table assume no citrate in the red cells. Previous work indicates that in normal blood no significant amount of citric acid is found in the red cell (11).

Analysis for citric acid, phosphorus, protein and total base of the $60 \mathrm{ml}$. portions of the blood removed from the infant during the transfusion is shown in Table II. These determinations were done on plasma.

A chart showing the changing citric acid levels with time, for the infant with no symptoms of erythroblastosis, is plotted in Figure 1.

TABLE II

Analysis for citric acid, phosphorus, total base and protein on the plasma of the blood removed in $60 \mathrm{ml}$. portions during a $500 \mathrm{ml}$. exchange transfusion

Seven portions removed for a total of $420 \mathrm{ml}$.

\begin{tabular}{|c|c|c|c|c|c|}
\hline $\begin{array}{c}\text { Plasma } \\
\text { sample } \\
\text { (in order of } \\
\text { removal) }\end{array}$ & $\begin{array}{l}\text { Phos- } \\
\text { phorus }\end{array}$ & $\begin{array}{l}\text { Total } \\
\text { base }\end{array}$ & $\begin{array}{c}\text { Total } \\
\text { protein }\end{array}$ & $\begin{array}{l}\text { Citric } \\
\text { acid }\end{array}$ & $\begin{array}{l}\text { Total citric } \\
\text { acid removed } \\
\text { in each } \\
60 \mathrm{ml} \text {. } \\
\text { sample of } \\
\text { whole blood* }\end{array}$ \\
\hline $\begin{array}{l}1 \\
2 \\
3 \\
4 \\
5 \\
6 \\
7\end{array}$ & $\begin{array}{c}\text { mg. \% } \\
7.5 \\
7.6 \\
6.8 \\
6.9 \\
6.4 \\
6.4 \\
6.3\end{array}$ & $\begin{array}{c}\text { meq./l. } \\
\text { - } \\
\text { - } \\
\overline{-} \\
155 \\
158\end{array}$ & $\begin{array}{c}\frac{\%}{5.21} \\
\overline{5.24} \\
5.34 \\
5.41 \\
5.81\end{array}$ & $\begin{array}{c}\text { mg. } \% \\
12.3 \\
25.4 \\
19.0 \\
22.4 \\
32.2 \\
34.4 \\
42.8\end{array}$ & $\begin{array}{r}m g . \\
4.4 \\
9.2 \\
6.4 \\
8.2 \\
11.6 \\
12.4 \\
15.9\end{array}$ \\
\hline
\end{tabular}

Total Citric Acid Removed $=68.1 \mathrm{mg}$.

* Calculated by assuming a $40 \%$ hematocrit and no citric acid in the red cells. $0.6 \times \mathrm{mg} . \%$ in plasma $\times 0.6$ $=$ total citric acid.

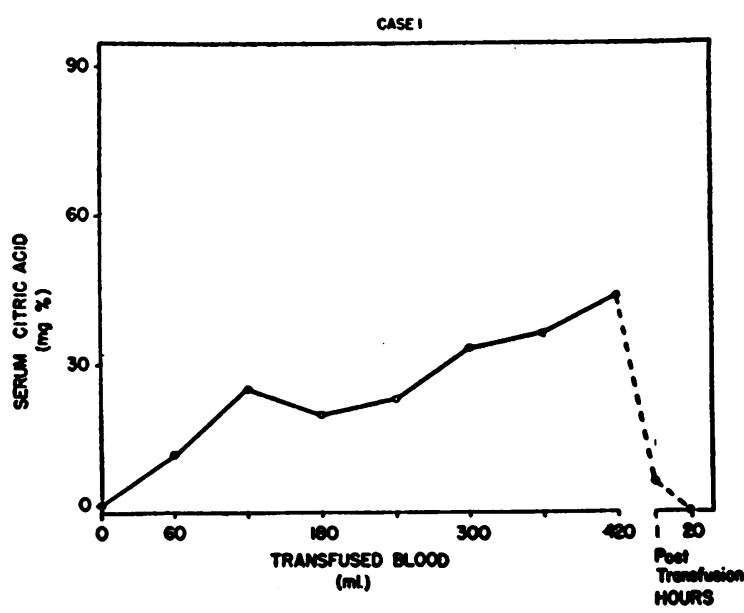

Fig. 1. Citric Acid Levels During an Exchange Transfusion with Citrated Blood on a Mongolord INFant with No Symptoms of Erythroblastosis or of Liver or Kidney Damage

In the eight cases of newborns with symptoms of erythroblastosis the determinations had to be limited to blood obtained during the transfusion. With the exception of Cases 2 and 6 the first sample obtained followed the administration of about $50-60 \mathrm{ml}$. of donor's blood and thus already contained added citrate. During the course of the transfusion, whenever symptoms of tetany or convulsions were impending or apparent, $5 \mathrm{ml}$. of a $10 \%$ solution of calcium gluconate were injected intravenously. In some instances, calcium gluconate was administered at various points in the procedure whether symptoms were or were not present.

The results obtained in six of these cases are shown in Figure 2. The scales of the graphs for Cases 3 and 4 are different with respect to citrate administered from that for Cases 5-8. In the first two cases $500 \mathrm{ml}$. of blood were infused, in the last four $1000 \mathrm{ml}$. of blood were used. Points at which calcium gluconate was administered are indicated with an arrow. These infants survived and have been followed for a period of at least six months and are all well. The details of their clinical course are incorporated in another report (17).

One infant in this series died within 24 hours after the transfusion. The changing citric acid levels for this infant are shown in Figure 3. On postmortem examination the liver of this child showed severe necrosis. 


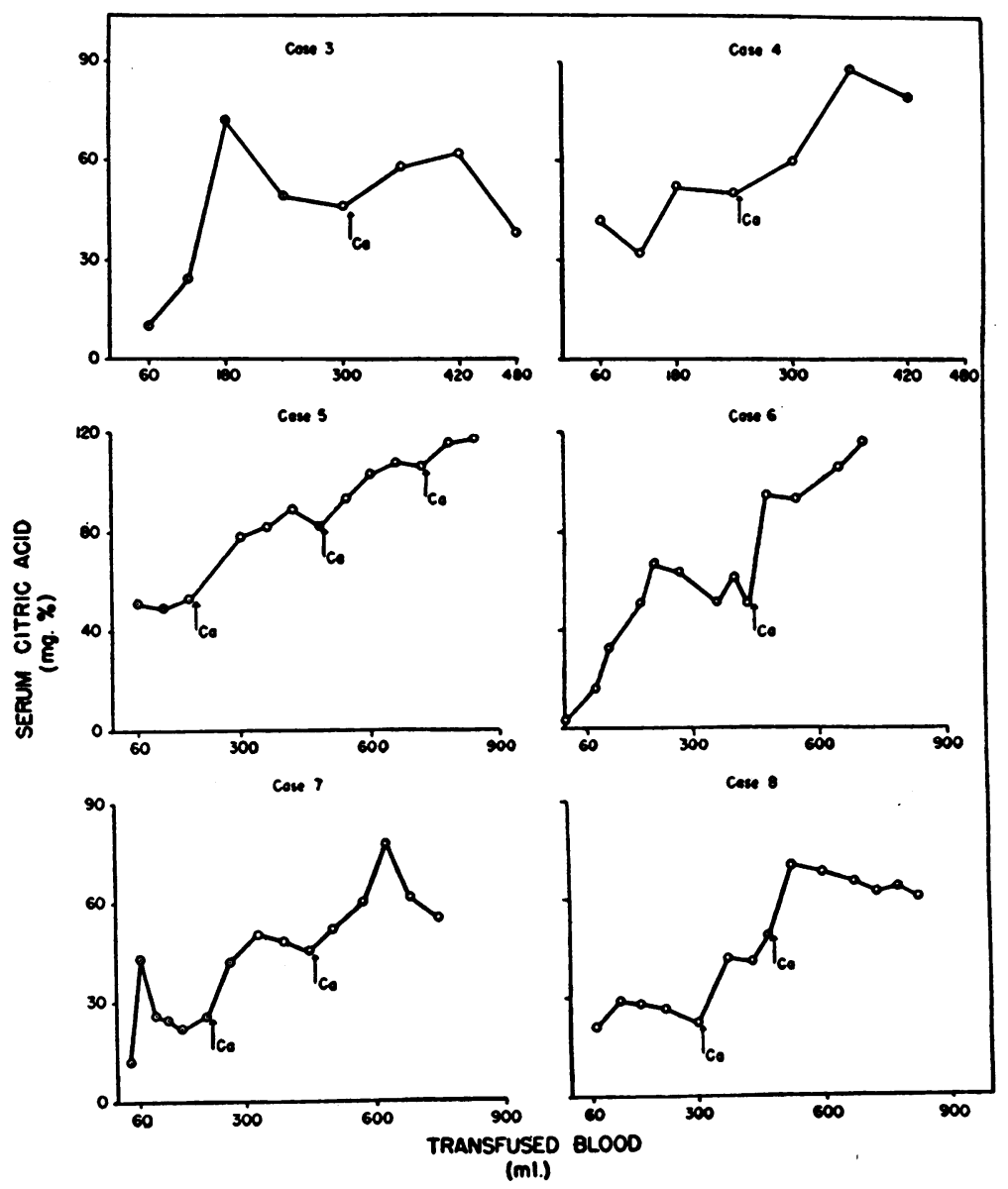

Fig. 2. Citric Acid Levels on Six Erythroblastotic Infants Treated with Exchange Transfusions with Citrated Blood. Effect of Administration of Calcium on the Citrate Level

Arrows indicate time of injection of calcium gluconate.

In view of the fact that we were unable to obtain the true total calcium values on the plasma of the infant with no symptoms of erythroblastosis fetalis, we studied the changing calcium values in a child with erythroblastosis fetalis during treatment with exchange transfusions. The bloods were dried at $100^{\circ} \mathrm{C}$. and ashed in a muffle furnace at $475^{\circ} \mathrm{C}$. before analysis so as to remove citrate interference. The results are shown in Figure 4 and Table III.

\section{DISCUSSION}

Examination of Tables I and II indicates a remarkable ability of the infant with no apparent liver or kidney damage to remove citric acid from the blood stream rapidly. After the addition of $60 \mathrm{ml}$. of citrated blood the citric acid level in the plasma of the infant should rise, according to calculations, to approximately $60 \mathrm{mg} . \% .^{3}$ Actually, after the adding of the first $60 \mathrm{ml}$. of citrated blood, the level rises to $10 \mathrm{mg} . \%$. In this infant the citric acid level never rose above $40 \mathrm{mg} . \%$ while

8 This figure is arrived at by assuming a $275 \mathrm{ml}$. blood volume and a hematocrit which is the same in the administered and endogenous blood. With a $40 \%$ hematocrit the infant's plasma volume would be $165 \mathrm{ml}$. For a 3 mg.\% citric acid level in the plasma the total citric acid in this plasma would be $5 \mathrm{mg}$. Sixty $\mathrm{ml}$. of citrated blood would contain $36 \mathrm{ml}$. of plasma with a citric acid concentration of $340 \mathrm{mg} . \%$ as determined. The citric acid content of this plasma would be $122.5 \mathrm{mg} . \%$. The total citric acid in the combined volume of blood plasma $(165+36=201 \mathrm{ml}$.) would then be $122.5+5=127.5$ mg. Expressed in mg.\% this would be $127.5 / 2.01=63.5$ $\mathrm{mg} . \%$. 


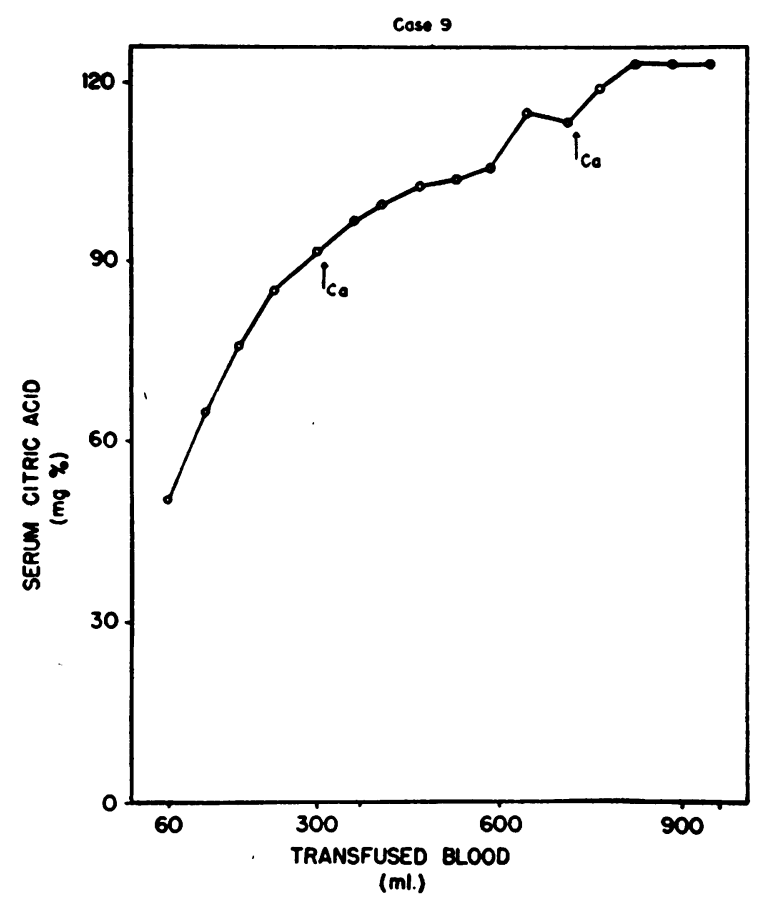

Fig. 3. Citric Acid Levels During an Exchange Transfusion on an ERythroblastotic Infant Who Did Not Survive for More Than 48 Hours After the Transfusion

Arrows indicate time of calcium gluconate injection.
TABLE III

Calcium determination on ashed blood plasma removed from an infant with symptoms of erythroblastosis during an exchange transfusion (see Figure 4)

\begin{tabular}{c|c|c|c|c|c|c|c|c|c|c}
\hline \hline $\begin{array}{c}\text { Amt. of } \\
\text { blood } \\
\text { transfused }\end{array}$ & $\begin{array}{c}\text { Pre- } \\
\text { trans- } \\
\text { fusion }\end{array}$ & 60 & 120 & 180 & $240 *$ & 300 & 360 & $420 *$ & 480 \\
\hline $\begin{array}{c}\text { Calcium } \dagger \\
m g . \%\end{array}$ & 10.0 & 12.8 & 14.5 & 15.3 & 24.0 & 21.0 & 15.4 & 19.0 & 17.0 \\
\hline
\end{tabular}

* After $5 \mathrm{ml}$. of $10 \%$ calcium gluconate were added.

$\dagger$ Determined on ashed plasma.

the blood infused contained a concentration of 340 mg.\%. According to the equation derived by Wiener (5), at the end of a $500 \mathrm{ml}$. transfusion $85 \%$ of the infant's blood has been replaced by the blood of the donor. At the end of a $1000 \mathrm{ml}$. transfusion $98 \%$ of the infant's blood has been replaced. As early as one hour after the termination of the procedure the level had dropped to almost the fasting level. The fasting level for newborn is of the order of $2-3 \mathrm{mg} . \%$ as reported previously (18, 19). A sample taken 19 hours later showed a level within the normal range.

In the last column of Table II are listed the actual quantities of citric acid that were removed from the infants at intervals during the procedure.

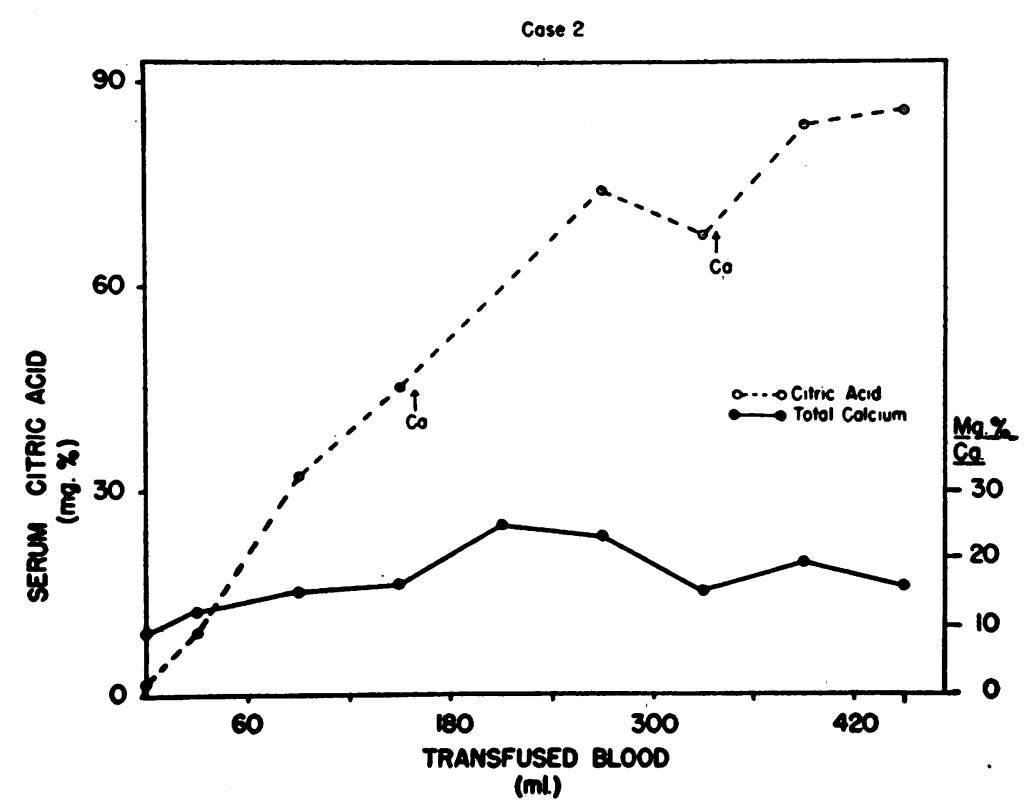

Fig. 4. Citric Acid and Total Calcium Levels During an Exchange Transfusion on an ERYThroblastotic Infant

Arrows indicate time of injection of calcium gluconate. 
These total $68 \mathrm{mg}$. as contrasted with $1,020 \mathrm{mg}$. infused. The infant retained $952 \mathrm{mg}$. This would indicate a retention of approximately $94 \%$ of the citrate injected. Only $71 \mathrm{mg}$. remained in the blood stream at the end of the procedure when the plasma level was $42.6 \mathrm{mg} . \%$. This is calculated on the assumption of a volume of $275 \mathrm{ml}$. and a hematocrit of $40 \%$.

Examination of Figures 2-4 indicates that the ability to lower citric acid levels in the plasma is somewhat impaired in the erythroblastotic infants transfused. Cases 4, 5, 7 and 9 show an immediate elevation of citric acid levels after the administration of the first $60 \mathrm{ml}$. of citrated blood, to a level of more than $30 \mathrm{mg} . \%$. Case 9 , who died, showed the highest level at this point $(52 \mathrm{mg} . \%)$. It is of interest to compare these curves with that of the infant who showed no symptoms of erythroblastosis. Comparison can only be made on the part of the curve obtained before the administration of calcium gluconate, since injection of this material causes changes which will be discussed below.

Each point on the curves represents the addition of $60 \mathrm{ml}$. of citrated blood. All cases, with the exception of the infant who died (Figure 3) showed spontaneous lowering of citric acid levels in the face of continued administration of citrate. Thus all the cases which survived, with the exception of Case 5 , showed lowering of citric acid levels after the initial rise, indicating a more rapid removal at these points than the rate at which the citrate was added. It is of interest to note that Case 5 clinically was the most severely affected of those who survived. Yet it is apparent that this infant's response to the administration of citrate clearly showed a less impaired mechanism than that of the infant who died (Case 9). For example, after $180 \mathrm{ml}$. of citrated blood had been infused (approximately two-thirds the infant's original blood volume) the citrate level was at 50 mg.\%. At this same point in the transfusion Case 9 was at $78 \mathrm{mg} . \%$. Case 9 showed little resistance to the rising citric acid levels. Similar comparison of Case 9 with all the other cases clearly showed the lesser ability of this infant to lower plasma citric acid levels.

The fate of administered citrate is suggested by several experimental studies on animals. Rabbits injected with sodium citrate subcutaneously ex- hibit an increase in the size of the livers (20). This increase has been demonstrated to be due in part to an increase in liver glycogen following the administration of citric acid (21). It would appear, therefore, that in these cases of exchange transfusion the citric acid may be rapidly converted to glycogen and perhaps lipids.

That the major portion of this conversion takes place in the liver has been shown by the work of Sjöstrom (22). When livers of rabbits, dogs and cats were perfused with fluids containing sodium citrate in concentrations one hundred times as large as those found in normal sera, after a single passage the perfusate had a citrate concentration near to normal levels for that animal. When rabbit livers were then poisoned by allyl formate, the level of serum citrate rose and the perfused liver showed a markedly diminished ability to metabolize citrate. In confirmation of this, it has been found (23) that the concentration of citrate in the portal vein was regularly higher than that in the arterial blood.

The liver is, however, not the only organ involved in the removal of citrate from the blood stream. The kidney removes and concentrates citric acid. The level of citrate in the urine is approximately 15-50 times that of the serum (11). The concentration of citrate in the renal vein is $20 \%$ lower than that in the renal artery (23). Citrate is also metabolized in the musculature. Stoppani (24) has demonstrated rapid metabolism of injected citric acid in eviscerated dogs.

In conjunction with the clinical symptoms and in the light of autopsy findings on children who have died of erythroblastosis fetalis the observations on the lessened tolerance of erythroblastotic infants to administration of citrate may be traced to partial liver damage and perhaps concomitant kidney damage. The liver damage in the infant who died was so extensive, as observed on postmortem examination, that very little resistance could be offered to the rising citric acid values. We postulate, from their ability to remove administered citric acid from the blood stream, that the other infants who showed greater resistance to a rise in citric acid plasma levels, conversely, had lesser liver damage and therefore a greater chance of survival.

At all points where calcium gluconate was injected (Cases 2-9) a rise in citrate level followed. 
In this connection it is of interest that injection of calcium salts, or of parathormone to raise the calcium level causes a rise in endogenous citrate levels (25).

That administration of calcium gluconate seems to interfere with the removal of citrate from the blood plasma must not be construed, for obvious reasons, as counterindicating the use of calcium gluconate to prevent tetany during the procedure.

In the case where calcium values were studied during the transfusion (Figure 4) a rise in endogenous calcium was noted before administration of calcium gluconate. This probably comes from the body stores of calcium (skeleton). The response is remarkably rapid. Studies on sheep (26) have shown that injection of citrate causes a rise in serum calcium which drops to normal after the citrate has been removed from the blood stream. Steggerda (27) has shown that oral administration of citric acid will cause a retention of calcium in humans followed later by increase in excretion in the stools. Similarly, it is probably from the bone stores that the phosphorus values are maintained in the face of the continuous administration of citrated blood containing half the inorganic phosphorus found in the infant's serum. The rise of calcium would therefore represent an endogenous mechanism for combatting the lowering of calcium ion concentration when citrate is infused. For the usual exchange transfusion, especially those involving the transfusion of 1,000 $\mathrm{ml}$. of blood this needs to be supplemented by injection of calcium gluconate.

These findings may explain the clinical observations of numerous investigators on the use of citrate as the anticoagulant. Clinical experience with citrate in transfusions seems to indicate that it is a non-toxic anticoagulant (28). Further, large doses of citrate fed to animals over an extended period of time produced no toxic effects (29). The liver, the kidneys, the peripheral musculature and the bone stores all serve to lower citric acid levels or to neutralize their effect on calcium and magnesium ion concentration.

A marked disparity exists between the concentration of various blood constituents in the adult as compared with the newborn. Some of these differences are further enhanced by addition of sodium citrate to adult blood. Other than the change in citrate concentration the addition of $60 \mathrm{ml}$. of
$3 \%$ sodium citrate to $500 \mathrm{ml}$. of blood will raise the total base of the plasma from approximately 150 meq. $/ 1$ to about 175 meq./1 (determined as 178 meq. $/ 1) .4$ Table I compares the values for phosphorus, protein, total base, calcium and citric acid of the citrated adult blood with the blood plasma of the newborn with no symptoms of erythroblastosis.

Despite the fact that blood with a total base of 178 meq./1 was administered rapidly and "flushed through" the circulatory system the total base of the infant's blood remained within the normal range (145-155 meq./1). The protein rise was small and only apparent toward the end of the procedure. One hour after the procedure was ended the protein values were falling, they were below the original fasting level of the newborn 19 hours later. The fall in protein and the appearance of a mild jaundice at the end of 19 hours may indicate some liver damage. Within 48 hours after the procedure the infant showed no untoward effects. Phosphorus levels during and at the end of the transfusion remained close to that of the infant's pre-transfusion blood rather than assuming the phosphorus level of the donor's blood.

From the observations above it is apparent that citrate as an anticoagulant has advantages. When infused, as in an exchange transfusion, into the newborn it is readily metabolized and removed from the blood stream restoring the natural clotting capacity of the blood within one hour after the transfusion is complete. However, a reasonable amount of liver and kidney function must be present to make possible the removal of citrate, the readjustment of total base, protein and phosphorus levels to their natural level for the newborn.

Using the icterus index and low protein level as criteria, observed in the control 19 hours after the transfusion, it must be said that some temporary

$4500 \mathrm{ml}$. of adult blood would contain $300 \mathrm{ml}$. of plasma assuming a hematocrit of $40 \%$. With a total base of 150 meq. $/ 1,300 \mathrm{ml}$. of plasma would contain 45 meq. The molecular weight of the dihydrate of sodium citrate is 295. For our purposes it may be assumed to be 300 so that a $3 \%$ solution would contain 100 millimoles/1 or $300 \mathrm{meq} / 1$. Sixty $\mathrm{ml}$. of this solution would contain $18 \mathrm{meq}$. The total plasma volume of the $560 \mathrm{ml}$. of citrated blood would then be $300+60=360 \mathrm{ml}$. In this volume would be contained $45+18=63 \mathrm{meq}$. Expressed in meq./1 the citrated plasma would contain 175 meq./1. 
liver damage is produced in this process. However, in the infant with no symptoms of erythroblastosis recovery was observed 48 hours after the transfusion with return to normal icterus and protein level.

\section{SUMMARY}

1. Exchange transfusions were carried out on one mongoloid newborn with no symptoms of liver damage or erythroblastosis and on eight newborns suffering from erythroblastosis fetalis.

2. Serial studies done on the blood removed from the normal infant showed an effective homeostatic mechanism to be operative in the case of citrate, total base, phosphorus and total protein.

3. Administration of calcium gluconate interferes with the rate of citrate removal from the blood stream.

4. The liver, kidneys, musculature and bone stores appear to remove or neutralize the effect of high citrate levels in the blood stream.

5. The erythroblastotic infants showed impaired ability to remove citrate but showed themselves still capable of removing massive quantities of citrate from the blood stream.

6. With the exception of one case all infants seemed to metabolize citric acid more rapidly or at least as rapidly as it was infused in the early stages of the transfusion. In this case where the disease process was most severe citric acid levels rose steadily throughout the transfusion. The infant died within 24 hours.

The authors would like to express their appreciation to Dr. A. S. Wiener who kindly permitted us to use his cases for this study.

\section{BIBLIOGRAPHY}

1. Wiener, A. S., Wexler, I. B., and Grundfast, T. H., Therapy of erythroblastosis fetalis with exchange transfusion. Bull. New York Acad. Med., 1947, 23, 207.

2. Wallerstein, H., Substitution transfusion: a new treatment for severe erythroblastosis fetalis. Am. J. Dis. Child., 1947, 73, 19.

3. Diamond, L., Exhibit at International Congress of Pediatrics, New York, 1947.

4. Rosenblatt, P., Massive necrosis of liver following exchange transfusion for erythroblastosis fetalis. Am. J. Clin. Path., 1948, 18, 700.

5. Wiener, A. S., and Wexler, I. B., The use of heparin when performing exchange blood transfusions in newborn infants. J. Lab. \& Clin. Med., 1946, 31, 1016.
6. Shelling, D. H., and Maslow, H. L., Effect of sodium citrate, acetate and lactate on the ultrafiltrability of serum calcium. J. Biol. Chem., 1928, 79, 661.

7. McLean, F. C., and Hastings, A. B., The state of calcium in the fluids in the body. I. The conditions affecting the ionization of calcium. J. Biol. Chem., 1935, 108, 285.

8. McLean, F. C., and Hastings, A. B., A biological method for the estimation of calcium ion concentration. J. Biol. Chem., 1934, 107, 337.

9. Shear, M. J., and Kramer, B., Composition of bone. V. Some properties of calcium citrate. J. Biol. Chem., 1928, 79, 161.

10. Wiener, A. S., and Wexler, I. B., Experience with exchange transfusion in erythroblastosis fetalis. Blood, 1949, 4, 1.

11. Natelson, S., Lugovoy, J. K., and Pincus, J. B., Determination of micro quantities of citric acid in biological fluids. J. Biol. Chem., 1947, 170, 597.

12. Natelson, S., Pincus, J. B., and Lugovoy, J. K., Microestimation of citric acid; a new colorimetric reaction for pentabromoacetone. J. Biol. Chem., 1948, 175, 745.

13. Sobel, A. E., and Sobel, B. A., Microestimation of calcium in serum. J. Biol. Chem., 1939, 129, 721.

14. Fiske, C. H., and Subbarow, Y., Colorimetric determination of phosphorus. J. Biol. Chem., 1925, 66, 375.

15. Kingsley, G. R., Direct biuret method for determination of serum proteins as applied to photoelectric and visual colorimetry. J. Lab. \& Clin. Med., 1942, 27, 840.

16. Keys, A., Determination of total base in blood and other biological fluids. J. Biol. Chem., 1936, 114, 449.

17. Wexler, I. B., and Wiener, A. S. In preparation.

18. Lindquist, N., Occurrence of citric acid in the serum and urine of healthy infants. K. fysiogr. Sallask. Lund. Forh., 1935, 5, 17.

19. Salomonsen, L., On citric acid content of the blood in hemophilia neonatorum transitoria. Acta. paediat., 1939, 24, 36.

20. Lazard-Kolodny, S., and Mayer, A., The effect of subcutaneous injections of citric acid on the size of the liver of the rabbit. Ann. de Physiol., 1938, 14, 265.

21. MacKay, E. M., Carnl, H. O., and Wick, A. N., Antiketogenic and glycogenic activity of citric acid. J. Biol. Chem., 1940, 133, 59.

22. Sjöstrom, P., Citric acid in the blood serum in the diagnosis of the diseases of the liver and bile ducts; a methodological, experimental, and clinical study. Acta chir. Scandinav., Supp., 1937, 49.

23. Martensson, J., Experimental studies on citric acid metabolism in the animal organism. Skandinav. Arch. f. Physiol., 1938, 80, 303.

24. Stoppani, A. O. M., Diabetes and citric acid metabolism. Medicina, 1946, 6, 389. 
25. Alwall, N., Studies on the regulation of the citric acid content of the blood stream. V. Relation between calcium and citric acid in serum. Acta med. Scandinav., 1945, 122, 448.

26. Cunningham, I. J., New Zealand Dept. Agr. Ann. Report, Nutrition Research, 1933-34, pp. 24-5.

27. Steggerda, F. R., and Mitchell, H. H., The effect of the citrate ion on the calcium metabolism of adult human subjects. J. Nutrition, 1946, 31, 423.
28. Allen, J. G., Clark, D. E., Thornton, T. F., Jr., and Adams, $\mathrm{W}$ : E., The transfusion of massive volumes of citrated whole blood and plasma in man; clinical evidence of its safety. Surgery, 1944, 15, 824.

29. Krop, S., Gold, H., and Paterno, C. A., Toxity of hydroxyacetic acid after prolonged administration; comparison with its sodium salt and citric and tartaric acids. J. Am. Pharm. A., 1945, 34, 86. 